\title{
Acute and chronic haemodynamic effects of prazosin in left ventricular failure ${ }^{\star}$
}

\author{
LEON STEIN, PETER R FOSTER, ABRAHAM W FRIEDMAN, \\ JEAN STATZA, PAUL L MCHENRY \\ From the Krannert Institute of Cardiology, the Department of Medicine, Indiana University School of \\ Medicine and Wishard Memorial Hospital, Indianapolis, Indiana, USA
}

SUMMARY We evaluated the acute and chronic effects of prazosin treatment in 11 patients with chronic congestive heart failure, NYHA functional class III and IV. Before treatment mean arterial pressure averaged $100 \pm 15 \mathrm{mmHg}$, left ventricular filling pressure $29 \pm 11 \mathrm{mmHg}$, and systemic vascular resistance $2372 \pm 1121$ dynes s cm${ }^{-5}$. Prazosin administration resulted in haemodynamic improvement in all but one patient with significant lowering of the mean arterial pressure, left ventricular filling pressure, and systemic vascular resistance. Nine patients completed a 10-week course of ambulatory treatment. Five patients remained improved while four developed significant fluid retention; two of these had transient exacerbation of congestive heart failure. This was controlled by increasing diuretic and/or prazosin treatment. After 10 weeks all nine patients had advanced to NYHA functional class II. Repeat haemodynamic measurements disclosed complete haemodynamic tolerance in one patient while three other patients showed partial tolerance with a lower cardiac output $(\mathrm{CO})$ response to prazosin. The nine patients, however, still showed significant lowering of the mean arterial pressure, left ventricular filling pressure, as well as the systemic vascular resistance. Though pharmacodynamic tolerance was noted in four out of nine patients, beneficial clinical and haemodynamic effects could be demonstrated after 10 weeks of prazosin treatment in most patients.

Further evaluation of the long-term effects of prazosin in chronic congestive heart failure is warranted.

The search for an oral vasodilator effective in relieving symptoms in patients with congestive heart failure has led several investigators ${ }^{1-3}$ to evaluate prazosin. This quinazoline derivative produces alpha-adrenergic blockade, dilating both arteries and veins and providing a balanced reduction in preload and afterload. ${ }^{14}$ After initial promising reports in acute and chronic congestive heart failure $^{12}$ several investigators have reported tachyphlaxis during acute studies using continuous haemodynamic monitoring. ${ }^{56}$ The relevance of this acute phenomenon to chronic ambulatory treatment is uncertain, since other investigators have reported sustained benefit during chronic ambulatory treatment. ${ }^{2} 8$ Drug tolerance during chronic prazosin treatment has been described less frequently. ${ }^{910}$ Long-term controlled studies with a large study population will eventually

*Supported in part by the Herman C Krannert Fund; and by grants from the National Heart, Lung and Blood Institute of the National Institutes of Health.

Received for publication 27 May 1980 be needed to resolve these conflicting results. In most reported chronic studies the patients have been evaluated by non-invasive means. The present study was designed to test the effects of prazosin during acute and chronic treatment for congestive heart failure over a 10-week period with sequential invasive haemodynamic measurements.

\section{Subjects and methods}

Eleven patients were initially evaluated and nine completed the 10-week study. Their clinical features are listed in Table 1. There were seven men and four women aged 55 to 77 (mean 61 years). All patients had chronic congestive heart failure (mean duration 5.3 years). Each patient entered the study after a period in hospital for decompensated congestive heart failure (NYHA class III or IV) while receiving digitalis and diuretics. The aetiology was atherosclerotic heart disease in seven patients and cardiomyopathy in four. 


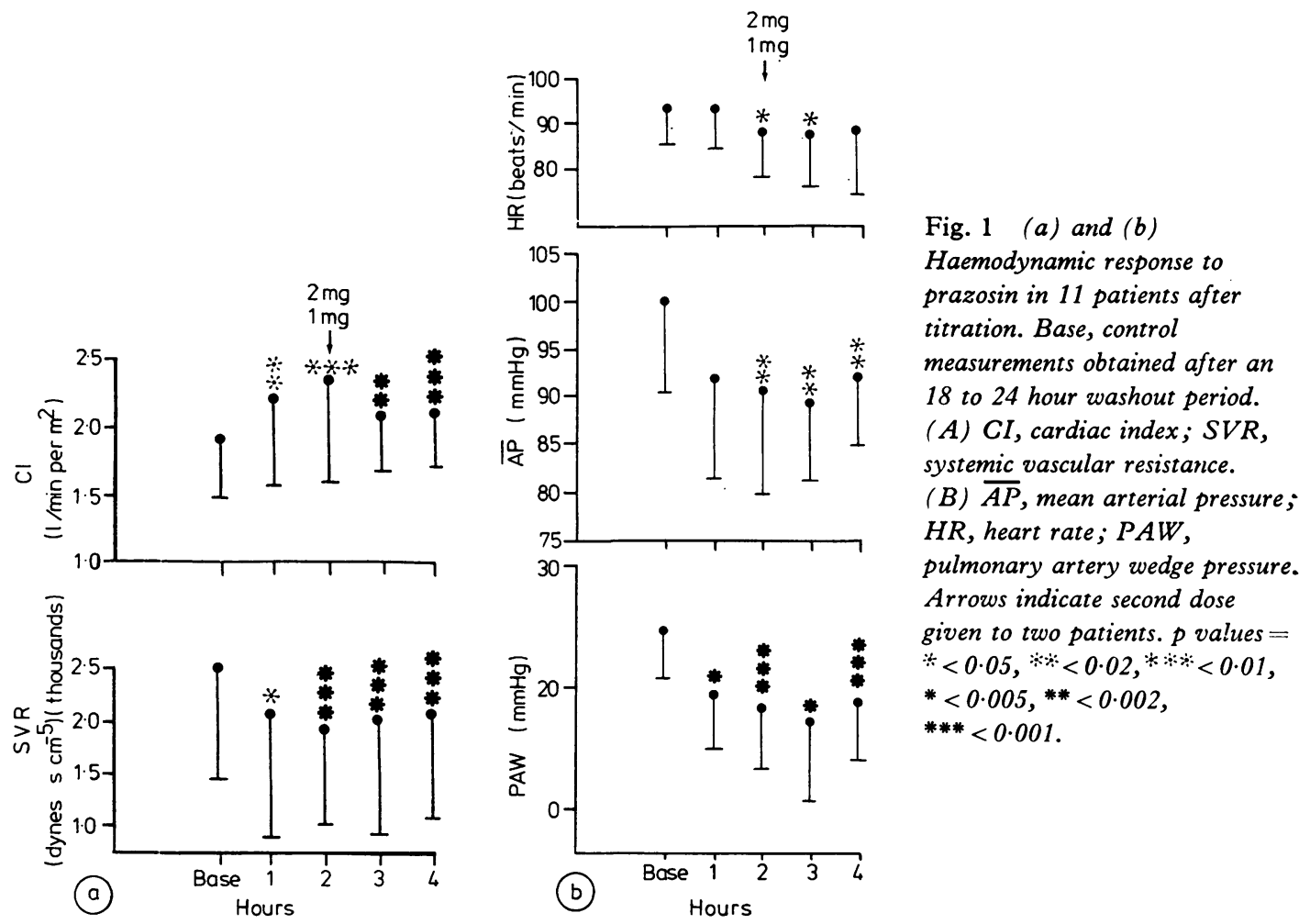

\section{STUDY DESIGN}

The study was divided into three phases. An initial inpatient pretreatment evaluation and titration with prazosin (phase I); an outpatient follow-up period lasting nine weeks (phase II); and a readmission for a final evaluation (phase III).

\section{Phase I}

After informed consent the patients had right heart catheterisation and then entered into the study if their left ventricular filling pressure exceeded $15 \mathrm{mmHg}$ and the cardiac index was less than $2.51 /$ min per $\mathrm{m}^{2}$.

The patients were titrated slowly with increasing doses of prazosin on an eight hour schedule until maximum benefit was felt to be achieved as determined by daily assessment of their symptoms and signs of congestive heart failure. This took an average dose of $5 \cdot 6 \pm 2 \cdot 2 \mathrm{mg}$ every eight hours, and an average of six days. Prazosin was then withheld

Table 1 Clinica data

\begin{tabular}{|c|c|c|c|c|c|c|c|}
\hline $\begin{array}{l}\text { Case } \\
\text { no. }\end{array}$ & $\begin{array}{l}\text { Age } \\
\text { (y) }\end{array}$ & Race & Sex & $\begin{array}{l}\text { Duration } \\
C H F(y)\end{array}$ & Diagnosis & $\begin{array}{l}\text { NYHA } \\
\text { class }\end{array}$ & Treatment \\
\hline $\begin{array}{r}1 \\
2 \\
3 \\
4 \\
5 \\
6 \\
7 \\
8 \\
9 \\
10 \\
11\end{array}$ & $\begin{array}{l}65 \\
61 \\
77 \\
54 \\
55 \\
62 \\
57 \\
65 \\
52 \\
64 \\
57\end{array}$ & $\begin{array}{l}\text { B } \\
\mathbf{B} \\
\mathbf{C} \\
\mathbf{B} \\
\mathbf{B} \\
\mathbf{B} \\
\mathbf{B} \\
\mathbf{C} \\
\mathbf{B} \\
\mathbf{B} \\
\mathbf{C}\end{array}$ & $\begin{array}{l}\text { M } \\
\text { F } \\
\text { F } \\
M \\
\text { F } \\
\text { F } \\
\text { F } \\
M \\
\text { F } \\
M\end{array}$ & $\begin{array}{r}8 \\
6 \\
5 \\
4 \\
10 \\
4 \\
3 \\
3 \\
3 \\
1 \\
10\end{array}$ & $\begin{array}{l}\text { ASHD } \\
\text { Cardiomyopathy }{ }^{\star \star} \\
\text { Cardiomyopathy } \\
\text { ASHD } \\
\text { Cardiomyopathy } \\
\text { ASHD } \\
\text { ASHD } \\
\text { ASHD } \\
\text { Alcoholic cardiomyopathy } \\
\text { ASHD } \\
\text { ASHD }\end{array}$ & $\begin{array}{l}\text { IV } \\
\text { IV } \\
\text { III } \\
\text { IV } \\
\text { IV } \\
\text { IV } \\
\text { III } \\
\text { IV } \\
\text { IV } \\
\text { IV } \\
\text { III }\end{array}$ & $\begin{array}{l}\text { Digoxin, dyrenium } 50 \mathrm{mg} \text {, hydrochlorothiazide } 25 \mathrm{mg} \\
\text { Digoxin, hydrochlorothiazide } 25 \mathrm{mg} \\
\text { Digoxin, frusemide } 120 \mathrm{mg} \\
\text { Digoxin, frusemide } 120 \mathrm{mg} \\
\text { Digitoxin, frusemide } 80 \mathrm{mg} \\
\text { Digoxin, frusemide } 200 \mathrm{mg} \\
\text { Digitoxin, dyrenium } 50 \mathrm{mg} \text {, hydrochlorothiazide } 25 \mathrm{mg} \\
\text { Digoxin, frusemide } 160 \mathrm{mg} \\
\text { Digoxin, frusemide } 80 \mathrm{mg} \\
\text { Digoxin, frusemide } 80 \mathrm{mg} \\
\text { Digoxin, frusemide } 160 \mathrm{mg}\end{array}$ \\
\hline
\end{tabular}

ASHD, arteriosclerotic heart disease; B, black; C, Caucasian.

$\star \star$ Cerebrovascular accident at 5 weeks, dropped from study. 
and after an 18 to 24 hour washout period the patients had repeat haemodynamic studies. Measurements were determined immediately before and half, one, two, three, and four hours after administration of prazosin at the last titrated dose. Two patients received a second dose of 2 and $1 \mathrm{mg}$ of prazosin, respectively, after two hours because their haemodynamic responses were felt to be less than optimal (Fig. 1).

\section{Phase II}

Those patients showing a beneficial response were discharged and followed weekly as out-patients for nine weeks. Pill counts were performed to assess compliance. During this period the dose of prazosin and/or diuretics was adjusted when clinically indicated.

\section{Phase III}

Patients were readmitted to the hospital for a final evaluation. Prazosin was again withheld for 18 to 24 hours and a haemodynamic study repeated in the same manner as after the initial titration in phase $I$.

\section{HAEMODYNAMIC STUDIES}

All haemodynamic studies were performed in the postabsorptive state and measurements were obtained one hour after the catheters had been placed.

Pulmonary artery, pulmonary artery wedge, and right atrial pressures were measured with a thermodilution balloon tipped Swan-Ganz catheter. Systemic arterial pressure was measured via a Teflon 'catheter introduced into a femoral artery. Pressures were recorded continuously on a six channel Gould Brush 260 Recorder. Mean pressures were derived electronically. Cardiac output was measured with a computer (Edwards 5200) as the average of three determinations with a variation of less than 10 per cent. Derived measurements included:

$$
\text { Cardiac index }(\mathrm{CI})=\frac{\mathrm{CO}}{\mathrm{BSA}} 1 / \mathrm{min} \text { per } \mathrm{m}^{2} \text {, }
$$

where $\mathbf{B S A}=$ body surface area.

Stroke volume index $(\mathrm{SVI})=\frac{\mathrm{CI}}{\mathrm{HR}} \mathrm{ml} / \mathrm{m}^{2}$,

where $H R=$ heart rate in beats per minute.

Systemic vascular resistance $($ SVR $)=$

$$
\frac{\overline{\mathrm{AP}}-\mathrm{RAP} \times 80}{\mathrm{CO}} \text { dynes } \mathrm{s} \mathrm{cm}^{-5}
$$

where $\overline{\mathrm{AP}}=$ mean arterial pressure and 80 is the conversion factor for converting units of resistance into dynes. $\mathrm{RAP}=$ right atrial pressure.

Stroke work index $(\mathrm{SWI})=\mathrm{SVI} \times(\overline{\mathrm{AP}}-\mathrm{PAW}) \times$ $0.0136 \mathrm{~g} \mathrm{~m}$ beats $/ \mathrm{m}^{2}$. PAW $=$ pulmonary artery wedge pressure.

Table 2 Haemodynamic data before and during treatment

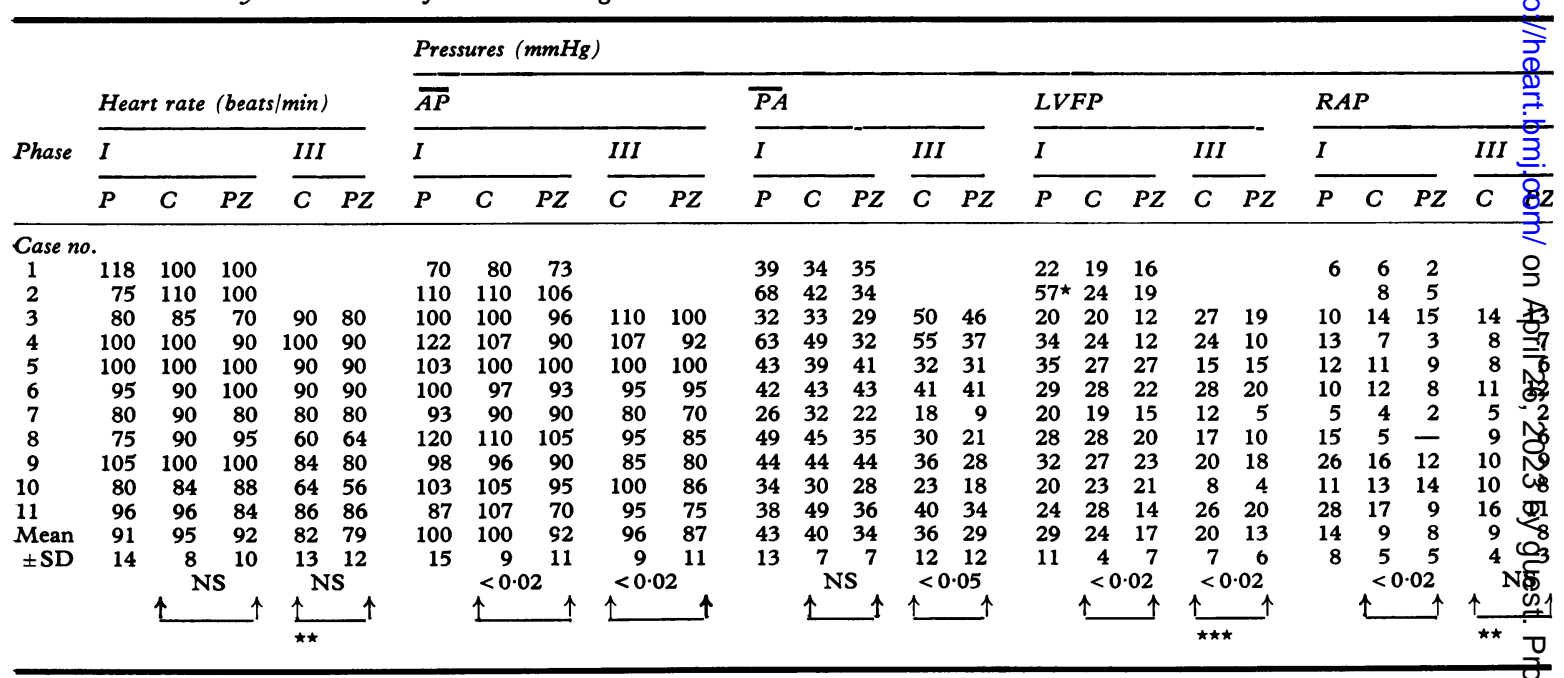

$\overline{\mathrm{AP}}$, mean arterial pressure; C, control; CI, cardiac index; LVFP, left ventricular filling pressure; measured as pulmonary artery wađ pressure except * is pulmonary artery diastolic pressure; $\mathrm{P}$, pretreatment baseline; $\overline{\mathrm{PA}}$, mean pulmonary artery pressure; PZ, peak effect of prazo phase I, initial haemodynamic studies first week; phase III, haemodynamic studies at 10 weeks; RAP, right atrial pressure; SVI, stroke volume ind SVR, systemic vascular resistance; SWI, stroke work index.

$\star \star p<0.05$ and $\star \star \star p<0.005$ when comparing control values during phase III with pretreatment baseline. 
STATISTICAL ANALYSIS

The data were analysed by analysis of variance except for the hourly measurements shown in Fig. 1 and 2 which were analysed using Student's paired t test. The null hypothesis was rejected with $\mathbf{p}<0.05$. Results are expressed as mean \pm SD.

\section{Results}

\section{CLINICAL COURSE}

The in-hospital titration phase was completed by 11 patients and 10 patients reported an improvement in their symptoms of dyspnoea and/or fatigue. One patient showed no clinical or haemodynamic improvement and was dropped from the study. Of the 10 patients who entered the ambulatory phase, one had a cerebrovascular accident during the fifth week of treatment and was dropped from the study. This patient remained subjectively improved until then. Nine patients completed the 10 weeks of treatment with prazosin. The clinical status of five patients continued to improve with gradual diuresis and weight loss, while four showed significant weight gain associated with clinical evidence of oedema. Of these four patients, three had increasing symptoms of dyspnoea and two had an overt exacerbation of left ventricular failure with reappearance of pulmonary râles. Prazosin was increased in all four patients and diuretics were increased in the three patients with increased symptoms of dyspnoea or signs of left ventricular failure. All four experienced a favourable response with the increase in drugs. All nine patients had improved to NYHA functional class II at the completion of the study. The mean prazosin dose of the nine patients averaged $5.5 \pm 2.4 \mathrm{mg}$ every eight hours before discharge and $6 \cdot 3 \pm 4 \mathrm{mg}$ after 10 weeks of prazosin treatment. Their baseline weight averaged $72 \cdot 6 \pm$ $17 \cdot 7 \mathrm{~kg}(160 \pm 39 \mathrm{lb})$ and was reduced to $61 \cdot 1 \pm 24 \cdot 5$ $\mathrm{kg}(148 \pm 54 \mathrm{lb})$ after 10 weeks of treatment (NS).

\section{HAEMODYNAMIC STUDIES}

The haemodynamic data are presented in Table 2 and Fig. 1 to 3. Table 2 shows the pretreatment, post-titration control measurements after washout and peak response to prazosin during the initial period in hospital (phase I), and the post-washout control measurements and peak response to prazosin after 10 weeks of treatment (phase III). Peak response was defined as the ventricular function curve with the simultaneous highest cardiac index and lowest pulmonary artery wedge.

Pretreatment heart rate averaged $91 \pm 14$ beats/ min, mean arterial pressure $100 \pm 15 \mathrm{mmHg}$, mean pulmonary artery pressure $43 \pm 13$, left ventricular filling pressure $29 \pm 11 \mathrm{mmHg}$, and cardiac index $1 \cdot 76 \pm 0.611 / \mathrm{min}$ per $\mathrm{m}^{2}$. The post-titration control haemodynamics after washout were not

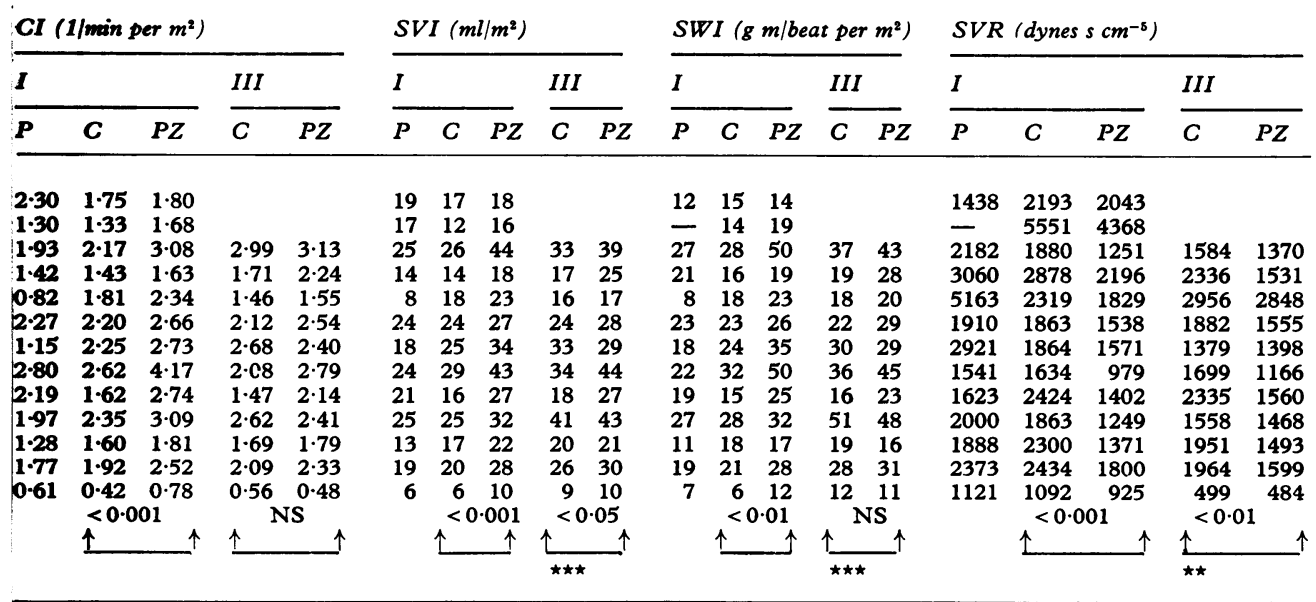


significantly different from the pretreatment measurements. After we administered prazosin a significant haemodynamic improvement was noted in all but one patient. This patient received a second dose of $2 \mathrm{mg}$ after two hours without benefit and was dropped from the study. The peak effect of prazosin usually occurred between one and two hours after administration and was significant for mean arterial pressure $(p<0.02)$, pulmonary artery wedge pressure $(p<0.02)$, right atrial pressure $(p<0.02)$, cardiac index $(p<0.001)$, stroke volume index $(p<0.001)$, stroke work index $(p<0.01)$, and systemic vascular resistance $(\mathrm{p}<0.001)$.

Fig. 1 shows the hourly changes in heart rate, mean arterial pressure, pulmonary artery wedge pressure, cardiac index, and systemic vascular resistance after titration with prazosin. The significant lowering of the mean arterial pressure, pulmonary artery wedge pressure, and systemic vascular resistance, and the increase in cardiac index was sustained during the four hour study period.

After 10 weeks of treatment with prazosin, and after another 18 to 24 hour washout period, there was a significant lowering of the heart rate $(p<0.05)$, pulmonary artery wedge pressure $(p<0.005)$, right atrial pressure $(\mathrm{p}<0.05)$, stroke volume index $(p<0.05)$, stroke work index $(p<0.005)$, and systemic vascular resistance $(p<0.02)$ when compared with the pretreatment baseline (Fig. 2, Table 2). One patient failed to respond to prazosin; but the group as a whole showed a significant reduction in mean arterial pressure $(p<0.02)$, mean pulmonary artery pressure $(p<0.05)$, pulmonary artery wedge $(p<0.02)$, stroke volume index $(p<0.05)$, and systemic vascular resistance $(p<0.01)$ when compared with the washout control measurements. The reduction in mean arterial pressure and pulmonary artery wedge pressure was sustained and remained significant during the four hours it was measured (Fig. 2, panel b). The cardiac index, however, failed to increase. The reason for this becomes clear when one compared the ventricular function curves in Fig. 2. During phase I, the control pulmonary artery wedge pressure was raised in all patients and after administration of prazosin all but one patient increased their cardiac index significantly as they
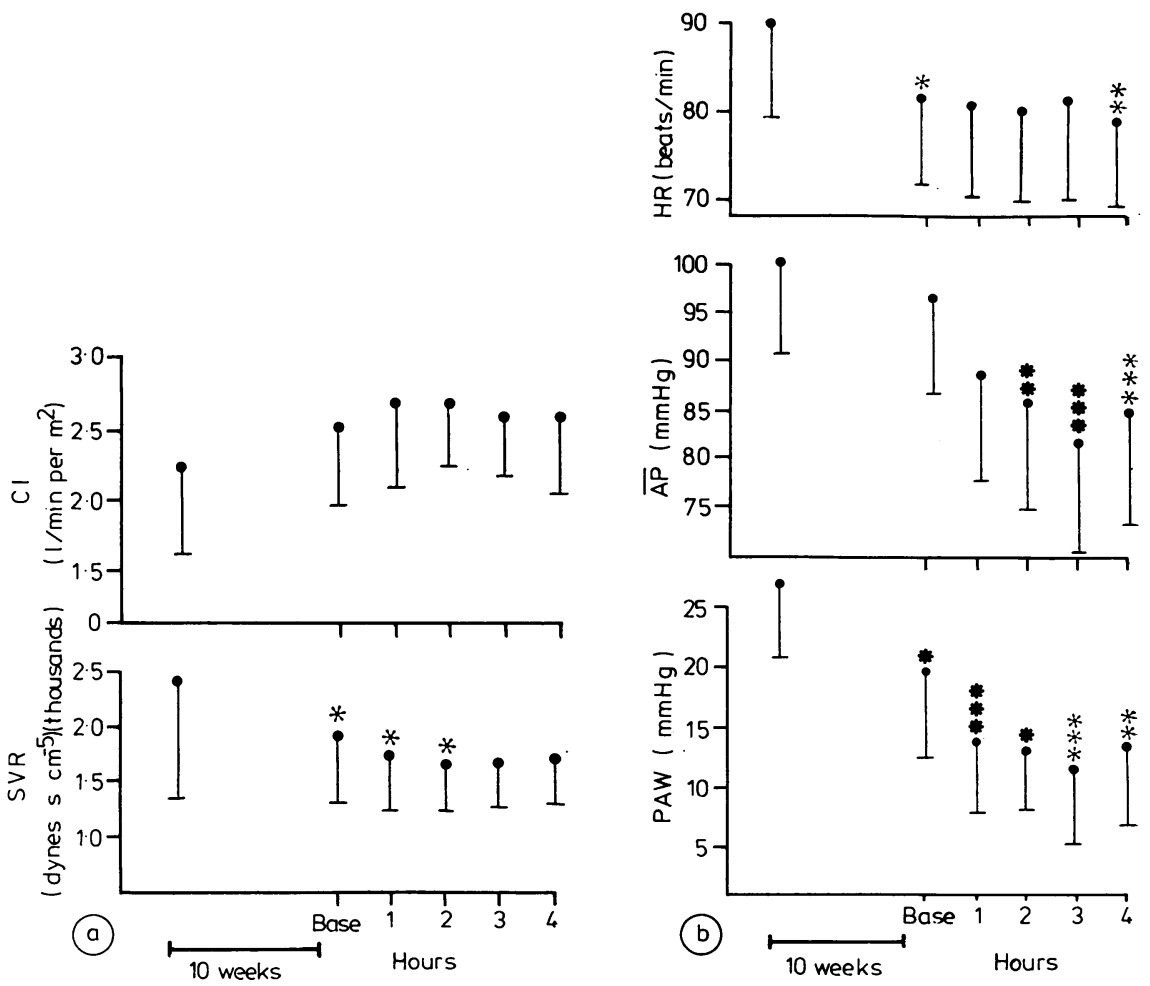

Fig. 2 Haemodynamic response in nine patients who completed 10 weeks of prazosin treatment. Control measurements are compared with pretreatment baseline. Abbreviations and symbols as in Fig. 1. 


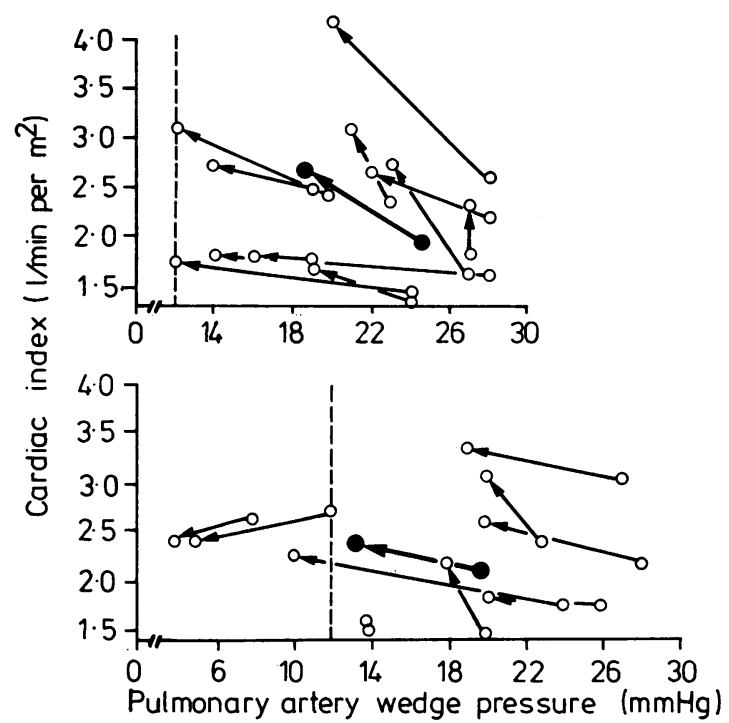

Fig. 3 Ventricular function curve showing peak changes in cardiac index and pulmonary artery wedge pressure after prazosin administration. Top panel shows the initial response in 11 patients. Bottom panel shows the response of the nine patients who completed 10 weeks of prazosin treatment. Heavy arrow and closed circles indicate mean response for the group. Dashed vertical lines show limit of normal pulmonary artery wedge pressure. For explanations see text.

lowered their pulmonary artery wedge pressure. During phase III control pulmonary artery wedge pressure was normal in two patients (8 and $12 \mathrm{mmHg}$ ) and their cardiac index dropped after administration of prazosin, probably because their pulmonary artery wedge pressure was reduced to suboptimal levels. Among the seven patients with a raised pulmonary artery wedge pressure, one failed to respond and showed total drug tolerance. Another patient had a significant lowering of the mean arterial pressure and pulmonary artery wedge pressure but his cardiac index did not increase. Five patients increased their cardiac index significantly though in two patients the increase was less than during phase $I$.

\section{Discussion}

Prazosin treatment improved symptoms of dyspnoea and fatigue in 10 of 11 patients to whom it was administered during inhospital titration. The clinical course of these patients differed during ambulatory treatment. In five patients, the clinical improvement was sustained and associated with gradual diuresis. Fluid retention was a significant problem in four patients, in two of whom there was transient exacerbation of left ventricular failure. This problem occurred early and required an increase in diuretic and/or prazosin treatment. After 10 weeks of prazosin treatment, however, all patients were symptomatically improved and had advanced to NYHA functional class II.

We were able to show a significant haemodynamic improvement in 10 out of 11 patients after initial administration and titration of prazosin treatment and this improvement was still evident in eight of nine patients who completed the 10 weeks of ambulatory prazosin treatment. Several investigators have recently reported pharmacodynamic tachyphylaxis to prazosin during short-term administration under haemodynamic monitoring, ${ }^{56}$ but others have failed to confirm this observation. ${ }^{11}$ This phenomenon is poorly understood and it may be manifest at rest but not during exercise. ${ }^{12}$

Our procedure for invasive haemodynamic assessment followed an 18 to 24 hour washout period. It is possible that the mechanisms causing tachyphylaxis reversed during this interval and responsiveness to prazosin was restored when readministered. All but one of our patients, however, reported clinical improvement at the start of the washout and haemodynamic studies. In three patients the improvement could have been related in part to the increase in diuretic treatment; this would not explain, however, the improvement in the other seven. Furthermore, we noted that after the final washout period there was a significant reduction in the control heart rate, pulmonary artery wedge pressure, right atrial pressure, stroke volume index, stroke work index, and systemic vascular resistance when compared with the pretreatment baseline. These results suggest a persistent effect of prazosin treatment after the drug had cleared from the plasma. Prazosin as well as hydralazine and minoxidil have been shown to remain in the blood vessel walls for longer periods. ${ }^{13}$ An alteration of the many feedback loops or endogenous chemicals, hormones, and neurotransmitters involved in the homeostasis of congestive heart failure during chronic prazosin treatment may be an additional or alternative explanation.

During the final administration of prazosin one patient failed to respond and three others showed a blunting of the cardiac index response. Blunting of haemodynamic responses has been previously reported during chronic prazosin treatment ${ }^{1011}$ and less frequently with hydralazine. ${ }^{14}$ Significant haemodynamic improvement was shown, however, in most of our patients after 10 weeks. If one were to accept the studies that show acute haemodynamic tachyphylaxis as the predictors of chronic effectiveness of prazosin treatment, one would not expect to 
see the beneficial responses observed in our patients or those patients reported in other long term studies. ${ }^{78} \mathrm{We}$, therefore, must question the clinical relevance of acute haemodynamic tachyphylaxis in predicting the effectiveness of chronic prazosin treatment for congestive heart failure. It has been shown that the acute haemodynamic changes produced by reserpine and propranolol during treatment for hypertension may be quite different from those that occur during chronic administration. ${ }^{13}$ For example, the cardiac output decreases during the initiation of treatment with reserpine but returns to control levels during chronic treatment. Propranolol increases the systemicvascular resistance acutely but lowers it during chronic treatment. This suggests that long term effects of vasodilator therapy cannot always be predicted with acute drug testing and are best examined with long term studies.

\section{Conclusions}

Our study indicates that in spite of the development of tolerance, significant haemodynamic benefits from prazosin can be shown in many patients for several weeks. Our results can only be considered preliminary as the number of patients was small, the study uncontrolled, and the follow-up extended to only 10 weeks. The differences in patient population and study design and the small number reported by others, usually in uncontrolled studies, make it difficult to reach definitive conclusions. We believe that the haemodynamic effectiveness of prazosin in congestive heart failure should be examined in a larger study population with double blind controlled studies to assess conclusively its value in the long term treatment of chronic congestive heart failure.

\section{References}

1 Miller RR, Awan NA, Maxwell KS, Mason DT. Sustained reduction of cardiac impedence and preload in congestive heart failure with the antihypertensive vasodilator prazosin. $N$ Engl f Med 1977; 297: 303-7.

2 Awan NA, Miller RR, DeMaria AN, Maxwell KS, Neumann A, Mason DT. Efficacy of ambulatory systemic vasodilator therapy with oral prazosin in chronic refractory heart failure. Concomitant relief of pulmonary congestion and elevation of pump output demonstrated by improvements in sympto- matology, exercise tolerance, hemodynamics and echocardiography. Circulation 1977; 56: 346-54.

3 Chatterjee K, Ports TA, Arnold S, Brundage B, Parmley W. Comparison of haemodynamic effects of oral hydralazine and prazosin hydrochloride in patients with chronic congestive heart failure. $\mathrm{Br}$ Heart $\mathcal{F} 1979$; 42: 657-63.

4 Mehta J, Iacona M, Pepine CJ, Conti CR. Comparison of haemodynamic effects of oral prazosin, oral hydralazine, and intravenous nitroprusside in same patients with chronic heart failure. Br Heart $\mathcal{F}$ 1979; 42: 664-70.

5 Packer M, Meller J, Gorlin R, Herman MV. Hemodynamic and clinical tachyphylaxis to prazosinmediated afterload reduction in severe chronic congestive heart failure. Circulation 1979; 59: 531-9.

6 Elkayam U, Lejemtel TH, Mathur M, et al. Marked early attenuation of hemodynamic effects of oral prazosin therapy in chronic congestive heart failure. Am $\mathcal{F}$ Cardiol 1979; 44: 540-5.

7 Aronow WS, Lurie M, Turbow M, Whittaker K, Van Camp S, Hughes D. Effect of prazosin vs placebo on chronic left ventricular heart failure. Circulation 1979; 59: 344-50.

8 Goldman SA, Johnson LL, Escala E, Cannon PJ, Weiss MB. Improved exercise ejection fraction with long term prazosin therapy in patients with heart failure. Am $\mathcal{F}$ Med 1980; 68: 36-42.

9 Awan NA, Miller RR, Maxwell KS, Mason DT. Development of systemic vasodilator tolerance to prazosin with chronic use of the agent in ambulatory therapy of severe congestive heart failure (abstract). Am $\mathcal{F}$ Cardiol 1978; 41 : 367.

10 Harper R, Claxton H, Middlebrook K, Anderson S, Pitt A. Acute and chronic effects of prazosin in severe congestive cardiac failure (abstract). Circulation 1979; 59 \& 60, suppl II : 129.

11 Feldman RC, Ball RM, Winchester MA, Jaillon P, Harrison DC. Absence of tachyphylaxis to the acute administration of prazosin in congestive heart failure (abstract). Circulation 1979; 59 \& 60, suppl II: 129.

12 Rubin SA, Chatterjee K, Gelberg HJ, Ports TA, Brundage BH, Parmley WW. Paradox of improved exercise but not resting hemodynamics with shortterm prazosin in chronic heart failure. Am $\mathfrak{F}$ Cardiol 1979 ; 43: 810-5.

13 Israili $\mathrm{ZH}$. Correlation of pharmacological effects with plasma levels of antihypertensive drugs in man. Ann Rev Pharmacol Toxicol 1979; 19: 25-52.

14 Walsh W, Greenberg B. Late results of oral hydralazine in patients with refractory heart failure (abstract). Circulation 1979; 59 \& 60, suppl II: 130.

Requests for reprints to Dr Leon Stein, Wishard Memorial Hospital, Indiana University Medical Center, 1001 West 10th Street, Indianapolis, Indiana 46202, USA. 